\title{
Article \\ Impact of Hydro-Alcoholic Solvents on the Oil and Phenolics Extraction from Walnut (Juglans regia L.) Press-Cake and the Self-Emulsification of Extracts
}

\author{
Pascale Subra-Paternault ${ }^{1}$, Maria del Pilar Garcia-Mendoza ${ }^{1,2}$, Raphaëlle Savoire ${ }^{1}$ \\ and Christelle Harscoat-Schiavo ${ }^{1, *}$
}

Citation: Subra-Paternault, P.; Garcia-Mendoza, M.d.P.; Savoire, R.; Harscoat-Schiavo, C. Impact of Hydro-Alcoholic Solvents on the Oil and Phenolics Extraction from Walnut (Juglans regia L.) Press-Cake and the Self-Emulsification of Extracts. Foods 2022, 11, 186. https: / /doi.org/10.3390/ foods11020186

Academic Editor: Verica Dragović-Uzelac

Received: 24 November 2021 Accepted: 22 December 2021 Published: 11 January 2022

Publisher's Note: MDPI stays neutral with regard to jurisdictional claims in published maps and institutional affiliations.

Copyright: (C) 2022 by the authors. Licensee MDPI, Basel, Switzerland. This article is an open access article distributed under the terms and conditions of the Creative Commons Attribution (CC BY) license (https:// creativecommons.org/licenses/by/ $4.0 /)$.
1 Institut Chimie et Biologie des Membranes et des Nano-objets (UMR 5248), Institut Polytechnique de Bordeaux, Centre National de la Recherche Scientifique, Université de Bordeaux, Allée Geoffroy Saint-Hilaire, 33600 Pessac, France; p.subra-paternault@cbmn.u-bordeaux.fr (P.S.-P.); pilargm23@hotmail.com (M.d.P.G.-M.); raphaelle.savoire@enscbp.fr (R.S.)

2 School of Basic Sciences, Technology and Engineering, Universidad Nacional Abierta y a Distancia (UNAD), Av. Roosevelt \# 36-60, 760042 Cali, Colombia

* Correspondence: christelle.harscoat-schiavo@u-bordeaux.fr
Abstract: The objective was to evaluate the performance of four hydro-alcoholic solvents to simultaneously extract oil and more polar molecules as phenolics, among others, to produce complex extracts that eventually could self-emulsify after solvent removal. Walnut press-cake was selected as the sourcing material. Extractions were performed as a semi-continuous operation up to a solvent-tosolid ratio of 28, with a fractional collection of the effluent. Among the solvents, labelled by their alcohol content EtOH 58, EtOH 86, iPro 60 and iPro 90 for ethanol (EtOH) and isopropanol (iPro), iPro 90 allowed to reach an oil extraction efficiency of $97 \%$ while the recovery for the other solvents was in the range of $30-40 \%$. For both alcohols, the increase of the solvent hydration negatively influenced the oil extraction but positively increased the recovery of phenolics that reached $17.6 \mathrm{mg}$ $\mathrm{GAE} / \mathrm{g}_{\text {cake }}$ when EtOH 58 was used. Several fractions contained enough surface-active material and oil to self-assemble as emulsions. IPro 90 and $\mathrm{EtOH} 86$ showed better performances in the sense that most extracts were able to emulsify, though extraction kinetics pointed out differences. The most hydrated solvents behaved equally, with extraction yields in the same range and a similar but limited emulsifying capacity of only few fractions.

Keywords: walnut press-cake; ethanol; isopropanol; extraction kinetics; phenolic compounds; emulsion

\section{Introduction}

Walnut (Juglans regia L.) is categorized as a strategic species for human nutrition by the food and agriculture organization (FAO) and their regular consumption is associated with the reduction of some disease risks, such as cancer and cardiovascular diseases [1]. Walnut oil is used as dressing oil because of its rich nutty flavor and health benefits [2] and as ingredient in cosmetic in dry skin creams, antiwrinkle and anti-aging products [3]. The oil production releases large quantities of partially defatted cakes whose market opportunities are increasingly considered. Though the walnut press-cake composition will depend on cultivars and the oil recovery process, it could be still remarkably rich in oil (18-36\%) and proteins (30-45\%) [3-5]. The residual oil still comprises less than $10 \%$ of saturated fatty acids and 62 to $77 \%$ of valuable polyunsaturated fatty acids [4-6]. Regarding proteins, the four major categories, albumin (water-soluble), prolamin (alcohol soluble), globulin (salt-soluble) and glutelin (soluble in dilute $\mathrm{NaOH}$ ) are in the range of $7 \%, 5 \%, 15-17 \%$ and $70-72 \%$, respectively $[7,8]$.

In recent years, much consideration has been given to the secondary metabolites of plants, specially to polyphenols that show antioxidant properties and potent effects in 
the prevention of diseases associated to oxidative stress [9]. With phenols content in the range of 10-35 mg GAE/g $g_{\text {cake }}$ [5,10-12], walnut press-cake could be harnessed as a cheap and available source of phenolic compounds that have moreover proven their capacity at preserving sensitive oils from oxidation [6,13-15]. The phenolic compounds of walnut press cake are mainly hydrolysable tannins and flavonols, the former accounting for $60-80 \%$ depending on the nut variety, while the flavonols vary from $26-35 \%$ [12,13]. Water, ethanol, methanol and acetone are the most-used solvents for preparing extracts of high antioxidant activities [1,16], but when low toxicity or food applications are targeted, ethanol-water mixtures become the only acceptable solvent. Such mixtures were used to extract phenolics from walnuts $[13,17,18]$.

The oil's demand is in constant increase due to nutritional and industrial issues. Large scale facilities of oil recovery are based on a two-step process, involving first a mechanical extraction by pressing followed by a hexane extraction stage to exhaust the press-cake. There is also a range of seeds for which mechanical extraction is not satisfactory, such as hard seeds and oil-poor seeds [19]. Safety, environmental and health concerns have prompted increased interest for alcohols as substitutes to hexane [20,21]. Due to its polarity, ethanol is a weaker solvent than hexane for triglycerides especially in the presence of water, but it can extract a greater variety of polar substances such as phospholipids, soluble sugars and phenolic compounds [22,23]. Isopropyl alcohol has also a high miscibility with oils and is more tolerant to water than ethanol in that the decrease of oil extraction yield with the hydration level of the solvent [24-26] or with the matrix moisture [27] is less pronounced. Compared to hexane, its use resulted in higher extraction rates and oil recoveries [27,28], though the reverse was also observed [29]. More polar molecules may be extracted along with the oil such as water, carbohydrates and proteins [26,30].

Oil-in-water emulsions are an integral part of many commercial products used in the food, supplements, personal care, cosmetic, detergent and pharmaceutical industries [31]. Emulsions are thermodynamically unstable systems made of small droplets of one liquid dispersed in another immiscible liquid whose stabilization is achieved by incorporating emulsifiers that adsorb at the interface of the two immiscible fluids. Many of the industrial surfactants are of synthetic origin, but more natural biobased alternatives are increasingly sought after [31-33] including in the form of biomass-based particles [34,35]. When used as emulsifiers, extracts are mostly obtained by water extraction in order to recover amphiphilic macromolecules such as proteins and polysaccharides [36-40], though polysaccharides such as saponins can be extracted by ethanol:water mixtures as well [41]. Emulsifying properties of protein hydrolysates or isolates obtained from walnut, specifically, were investigated by several authors [42-44]. Another class of surface-active molecules is lecithin, which is a mixture provided with diverse contents and types of phospholipids. Phospholipids can be recovered by water-ethanol mixtures at a yield that increases significantly with the ethanol content $[45,46]$. Generally speaking, emulsifying properties of extracts obtained by hydrated mixtures or non-aqueous solvents are rarely addressed in literature. Grape seeds tannins, obtained by acetone/water 60:40 v/v extraction followed by chromatography for purification, were found to stabilize emulsions [47]. As for non-aqueous solvent, Zhang et al. [48] prepared oil-in-water emulsions using as surfactant a rapeseed extract obtained by supercritical $\mathrm{CO}_{2}$. The addition of rapeseed extract at a concentration above $0.4 \%$ resulted in an emulsion stability comparable to the addition of $0.2 \%$ Tween 20 .

The aim of this work was to evaluate the performance of four solvents at producing complex extracts that would contain in their composition oil and polar molecules. By targeting nutritional extracts along with the valorization of a food by-product, we selected walnut press-cake as the source of healthy oil and polyphenols. This work is in the continuity of our previous study in which we focused on phenolic compounds using various methods for their extraction includinga semi-continuous technique with aqueous ethanol as extracting solvent [14]. In the present work, three other hydro-alcoholic solvents were investigated in order to recover at the same time lipophilic and hydrophilic molecules. As a proof of concept, the foreseen property of the extracts is their self-emulsification upon 
rehydration after the removal of the solvent. Compared to the literature cited above, we therefore intend to produce the oily phase and the emulsifiers by the extraction process itself. Varying the polarity of the solvent is thought to influence the oil and surface-actives content of the extract and thus influence the ability of the extracts to self-emulsify. The extractions were performed in a semi-continuous process that offers the opportunity of fractioning extracts and optimizing solvent-to-solid ratios. The performance of solvents was evaluated on the basis of global extraction yield, oil and polyphenols recovery and the emulsification potential of extracts.

\section{Materials and Methods}

\subsection{Walnut Cake}

The cake was kindly donated by Moulin de la Veyssière, Dordogne, France (www. moulindelaveyssiere.fr, accessed on 5 January 2022). The fruits, of the Lara variety, were grown locally and pressed under mild heating to recover the oil. The cake was stored at $-18^{\circ} \mathrm{C}$ after its collection. A batch of $100 \mathrm{~g}$ was ground and sieved below $600 \mu \mathrm{m}$ (Retsch, Germany) then stored at $-18{ }^{\circ} \mathrm{C}$. The proximate composition of the walnut press-cake was $3 \%$ moisture (measured by weight loss during drying at $105^{\circ} \mathrm{C}$ ), $27 \%$ protein (measured by Kjeldahl method using a conversion factor of 5.3), 37\% oil (measured by hexane Soxhlet extraction), $5 \%$ ash (by incineration at $500{ }^{\circ} \mathrm{C}$ for $24 \mathrm{~h}$ ) and $28 \%$ carbohydrates (estimated by mass difference).

\subsection{Solvents and Reagents}

Ethanol (EtOH, 96\%) and hexane were purchased from Atlantic Labo (Bruges, France), while 2-propanol (iPro, 99.8\%) was from Scharlau (Sharlab, Spain). Deionized water with a resistivity of $15 \mathrm{~m} \Omega \cdot \mathrm{cm}$ (ELGA, Purelab ${ }^{\circledR}$ Option, St. Neots, UK) was used to prepare hydro-alcoholic mixtures and emulsions. The use of ethanol 96 led to slightly different hydration levels for ethanol- and isopropanol-based mixtures. Solvents were labelled in reference to their alcohol content in vol\% as iPro 60, iPro 90, EtOH 58 and EtOH 86. Folin reagent, sulfuric acid, anthrone, glucose and gallic acid, were from Sigma-Aldrich (Saint-Quentin-Fallavier, France).

\subsection{Semi-Continuous Extraction}

The semi-continuous extraction consists in flowing the solvent through a bed of walnut cake particles and periodically collecting the effluent [14]. Briefly, five grams of grounded and sieved walnut cake were mixed with glass beads of $2 \mathrm{~mm}$ prior being loaded in an empty stainless steel column $\left(19.8 \mathrm{~cm} \times 0.9 \mathrm{~cm}\right.$ i.d.) housed in an HPLC oven set at $60^{\circ} \mathrm{C}$. The solvent, heated by a magnetic hotplate stirrer, was delivered at $1 \mathrm{~mL} / \mathrm{min}$ by an HPLC Waters dual pump. At the column exit, a capillary drove the effluent to a graduated tube immersed in ice that was changed periodically to collect fractions of $7 \mathrm{~mL}, 7 \mathrm{~mL}, 7 \mathrm{~mL}$, $22 \mathrm{~mL}, 44 \mathrm{~mL}$, and $44 \mathrm{~mL}$ for an entire extraction time of $140 \mathrm{~min}$. Experiments were randomly triplicated.

\subsection{Characterization}

The collected fractions were transferred to round flasks. An aliquot of $2 \mathrm{~mL}$ was sampled for total phenolic quantification while the rest was desolventized under vacuum by a rotary evaporator. The extracted amount in each fraction was quantified by the weight obtained after the solvent removal, taking into account the aliquoted $2 \mathrm{~mL}$. The global extraction yield is reported as cumulative extracted amounts per gram of cake.

The $2 \mathrm{~mL}$ aliquots were analyzed for the total phenolic content (TPC) after being vortexed and further filtered on PVDF 0.45 micron or/and centrifuged at 10,000 rpm for $20 \mathrm{~min}$ [14]. TPC of extracts was measured by the Folin-Ciocalteu method, using gallic acid as the standard and a calibration curve in a concentration range of 16-350 mg/L. Analyses were performed in duplicate. TPC data are reported in mg of Gallic Acid Equivalents (GAE) per $\mathrm{mL}$ of solvent or per gram of cake. 
The oil extraction yield, expressed in $g$ oil/gcake, was calculated using the mass of oil present in the cake before and after the hydroalcoholic extraction. Masses were obtained by submitting the cake residue to hexane extraction in Soxhlet apparatus (Tecator Soxtec ${ }^{\mathrm{TM}}$ HT2, Hillerød, Denmark) for $4 \mathrm{~h}$. The oil recovery (\%) represents the amount of oil extracted by hydro-alcoholic solvents divided by the initial oil amount in the raw cake.

The Soxhlet-defatted cake residues were analyzed for their protein content according to the Kjeldahl method using a conversion factor of 5.3 [49]. Analyses were duplicated.

\subsection{Emulsification}

The collected fractions were evaporated under vacuum to remove the solvent and determine the overall extraction yield. The content of the flask was then recovered by adding 4 or $5 \mathrm{~mL}$ of deionized water followed by sonication for $3 \mathrm{~min}$ in ultrasonic bath (model Sonorex, Bandelin, Germany, power: 80/240 W). Four mL was the minimum volume to wet the flask walls and recover the extract. The obtained dispersions were observed by optical microscopy (Olympus BX 51 and camera ColorView U-CMAD3, magnification $\times 10$ or $\times 20$, Olympus, Hamburg, Germany). Some dispersions were characterized by laser diffraction using water as the dispersion medium (Mastersizer 2000 equipped with a sample dispersion unit, Malvern Instrument, Orsay, France; He Ne gas laser, beam wavelength of $633 \mathrm{~nm})$. Samples were stored at $-18^{\circ} \mathrm{C}$.

\subsection{Statistical Analysis}

Results are presented as mean \pm standard deviation calculated from at least two replicates. Statistical evaluation was performed using the $\mathrm{R}$ freeware through the Rstudio interface. The significant differences $(p<0.05)$ were analyzed through Tukey's test.

\section{Results}

\subsection{Extraction Yields}

Extractions were carried out using EtOH58, EtOH86, iPro60 and iPro90 as solvents. Extraction yields obtained at the end of extraction, e.g., at a solvent-to-cake ratio of about $30 \mathrm{~mL}$ per $\mathrm{g}$, are reported in Table 1 for the total extracted amount, phenolic compounds and oil.

Table 1. Extraction yields of total extract $(n=3)$, total phenolic compounds $(n=2)$, oil $(n=3)$ and dielectric constants (Di) of solvents. Oil content of untreated walnut press-cake: $0.37 \pm 0.01 \mathrm{~g} / \mathrm{g}_{\text {cake }}$.

\begin{tabular}{|c|c|c|c|c|}
\hline Solvent & $\begin{array}{l}\text { Total Extract } \\
\left(g_{\text {extract/gcake }}\right)\end{array}$ & $\begin{array}{l}\text { Total Phenolics } \\
\text { (mg GAE/gcake) }\end{array}$ & $\begin{array}{l}\text { Oil Extraction } \\
\text { (g oil/g } \text { gake }_{\text {cake }}\end{array}$ & Di \\
\hline EtOH 58 & $0.21 \pm 0.01^{\mathrm{a}}$ & $17.6 \pm 0.3^{a}$ & $0.12 \pm 0.03^{a}$ & 43.3 \\
\hline EtOH 86 & $0.20 \pm 0.01^{\mathrm{a}}$ & $7.9 \pm 0.3^{b}$ & $0.14 \pm 0.03^{\mathrm{a}}$ & 28.9 \\
\hline iPro 60 & $0.20 \pm 0.02^{\mathrm{a}}$ & $14 \pm 1^{\mathrm{c}}$ & $0.12 \pm 0.02^{a}$ & 38.3 \\
\hline iPro 90 & $0.44 \pm 0.02^{b}$ & $3.6 \pm 0.2^{d}$ & $0.36 \pm 0.01^{b}$ & 20.7 \\
\hline
\end{tabular}

$\overline{\text { abcd }}$ Values with different superscript letters within a column are significantly different at $p<0.05$.

According to data, the overall extraction capability of the three solvents EtOH 58, EtOH 86 and iPro 60, was similar and in the range of $20 \mathrm{wt} \%$, while iPro 90 exhibited a singular superiority by extracting twice more amounts than other solvents.

For the extraction of phenolic compounds, the extraction capacity of the solvents varied significantly, with a superiority of ethanol versus isopropanol whatever the water content and a better performance of the most hydrated solvents. The solvent of best efficiency for phenols extraction was therefore EtOH 58, while iPro 90 was the worst. Aqueous solvents are effective mixtures to extract phenolics from walnut kernels [1]. The influence of the hydration level was more specifically reported by Fregapane et al. [13], who used $\mathrm{EtOH} 100, \mathrm{EtOH} 80, \mathrm{EtOH} 60$ and pure water to extract phenolics from pistachio kernels. The extraction rate increased deeply from 5.7 to $16.9 \mathrm{mg}$ GAE/g when the water content varied from 0 to $20 \%$ and then slowed down when the water content was further 
increased to $40 \%$ and 100\% (18.1-19.8 mg GAE/g). In Odabas and Koca [50], hazelnut skins were extracted by using $\mathrm{EtOH} 90, \mathrm{EtOH} 70$ and $\mathrm{EtOH} 50$. The TPC values increased with the solvent hydration from $37 \mathrm{mg} \mathrm{GAE} / \mathrm{g}$ (EtOH 90) to $59 \mathrm{mg} \mathrm{GAE} / \mathrm{g}$ (EtOH 50). It is worth noting that not only solubility but phenolics types, their interactions with the matrix and extractions conditions influence the recovery of components.

For oil extraction, there is evidence in the literature that short-chain alcohols such as ethanol and isopropanol could replace hexane in vegetable oils extraction [20,23,25-27,51,52], but the presence of water is detrimental to the oil solubility or recovery $[30,53-56]$. Our results are consistent with the trends reported in the literature, since a higher hydration level of the extracting solvent decreased the oil extraction yield. The best performance was hence achieved by iPro 90, which allowed the recovery of $98 \pm 1 \%$ of the oil initially present in the walnut cake, while the recovery for other solvents was of $32 \pm 7 \%$ for iPro 60 and $\mathrm{EtOH} 58$ and $36 \pm 7 \%$ for EtOH 87. Comparing now the overall and the oil extraction yields, it can be seen that oil represented a significant part of the global extract. The high extraction yield obtained with iPro 90 was therefore due to its higher capacity for extracting oil.

Comparing EtOH 100, EtOH 94, iPro 100 and iPro 88 as solvents, Navarro et al. [26] concluded to the best performance of iPro 100 for extracting corn germ-bran oil while ethanol and aqueous mixtures were better for the extraction of carbohydrates. To better appraise the difference of polarity, several authors [25,26,51] correlated the extraction capacity of solvents to their dielectric constant, which was considered as being a key parameter in determining solute-solvent interactions. Dielectric constants of mixtures were calculated (Table 1) and correlated to the various yields (Figure 1). Values were calculated using the equation proposed by Tir et al. [51], $\mathrm{Di}=\mathrm{Di}_{\mathrm{A}} \mathrm{w}_{\mathrm{A}}+\mathrm{Di}_{\mathrm{W}} \mathrm{w}_{\mathrm{W}}$, where $\mathrm{w}_{\mathrm{A}}$ and $\mathrm{w}_{\mathrm{W}}$ are mass fractions of alcohol $(\mathrm{A})$ and water $(\mathrm{W})$, respectively, and $\mathrm{Di}_{\mathrm{A}}$ and $\mathrm{Di}_{\mathrm{W}}$ are dielectric constants at $60{ }^{\circ} \mathrm{C}$ of pure alcohols [26] and pure water [57], respectively.

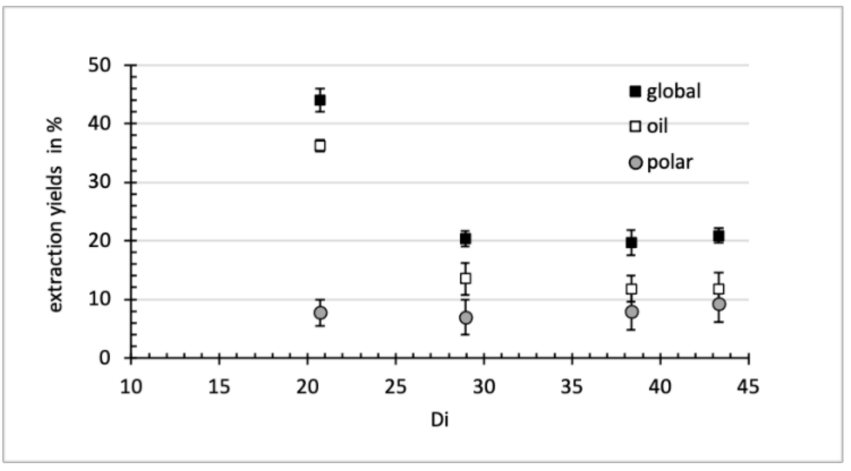

Figure 1. Relation between the various yields (global extraction, oil extraction, polar compounds extraction) and dielectric constant (Di) of the hydro-alcoholic solvents. The yield for polar compounds is calculated as the difference between the global and the oil yields.

The mixing of alcohols with water increased the dielectric constant of the prepared mixtures. The solvent of the lowest dielectric constant, isopropanol, exhibited the best performance for oil extraction, whereas solvents of higher Di (EtOH 86, EtOH 58, iPro 60) led to worse performances with no significant differences between them. In comparison, the yield of polar compounds extraction, evaluated by the difference between the global and the oil extraction yields, ranged between $7 \pm 3 \%$ and $9 \pm 3 \%$ but the difference was not statistically significant. By increasing the hydration level of solvents, the solvent increases its ability to extract non-oil compounds [21] such as carbohydrates [26] and proteins [27,54]. In the cited references, the trends were evaluated for ethanol- or isopropanol-based mixtures with a water content varying from 0 to $12 \mathrm{wt} \%$. It can be inferred that the $10-14 \%$ water content used in this work is sufficient to extract the majority of polar species, and that increasing this proportion beyond $10-14 \%$ has no additional impact.

The protein content of defatted cake residues obtained from extractions with hydroalcoholic solvents followed by Soxhlet extraction by hexane was evaluated (Figure 2). 


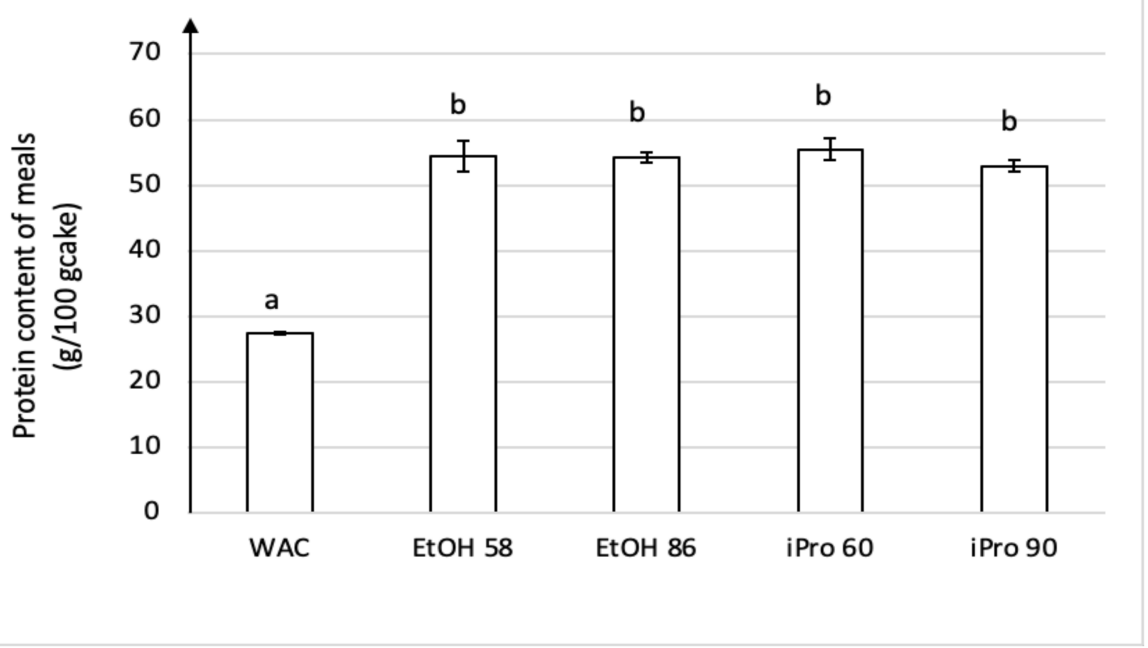

Figure 2. Protein content of meals obtained after extraction with hydro-alcoholic solvents followed by Soxhlet defatting with hexane. WAC label corresponds to the untreated walnut cake. ${ }^{\mathrm{ab}}$ Different letters mean significantly different values at $p<0.05$.

Due to the sequence of extractions, the protein content in the treated meals was higher than the protein content of the raw cake $\left(27.4 \pm 0.2 \mathrm{~g} / 100 \mathrm{~g}_{\text {cake }}\right)$. Statistics moreover confirmed that there was no significant effect of the extracting solvent on the cake residual protein content. This is consistent with the previous comment on the polar compounds extraction yield stating that a $10 \%$ water content in the extracting solvent was sufficient to extract most of the polar substances. In fact, proteins of the walnut kernel are mainly composed of glutelins (about 70\% of the kernel proteins) and globulins (about 18\%) that are soluble in dilute $\mathrm{NaOH}$ and saline media, respectively [8]. In the cited study, the extraction of walnut flour by EtOH 70 led to a low yield of about 3\% because of the presence in small proportion only of the alcohol-aqueous-soluble prolamins $[8,18]$. The effect of hydro-alcoholic extraction on the treated meal proteins was evaluated in literature for sesame cake [24], corn germ-bran pellets [26] and rice bran pellets [25] using absolute ethanol, $\mathrm{EtOH}$ at $6 \mathrm{wt} \%$ of water, absolute isopropanol and iPro at $12 \mathrm{wt} \%$ of water. At $60{ }^{\circ} \mathrm{C}$, only the cakes treated by absolute iPro showed a slightly higher protein content or nitrogen solubility index for corn germ- or rice bran-pellets, respectively, whereas for sesame, significant differences were not observed among the NSI values.

\subsection{Extraction Kinetics and Aspect of Collected Fractions}

Although the final global yields were similar for $\mathrm{EtOH} \mathrm{58,} \mathrm{EtOH} 86$ and iPro 60 (Table 1), there was significant differences in the extraction kinetics (Figures 3 and 4).

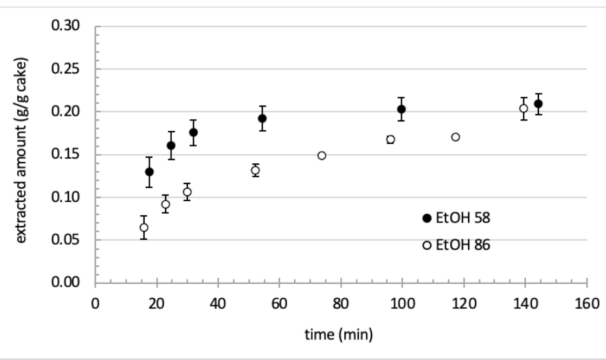

(a)

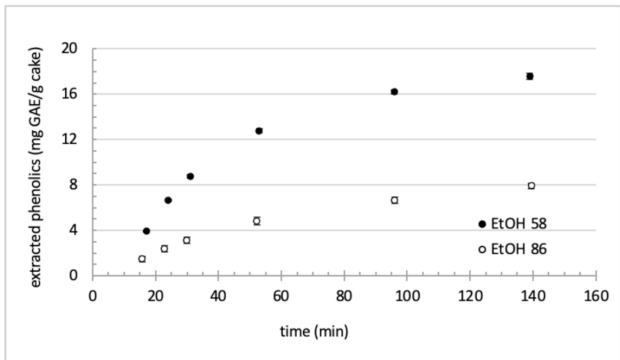

(b)

Figure 3. Extraction kinetics of (a) global extract and (b) total phenolic compounds using ethanolbased solvents. 


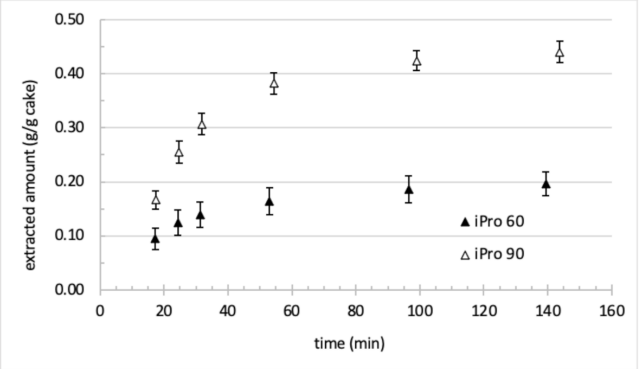

(a)

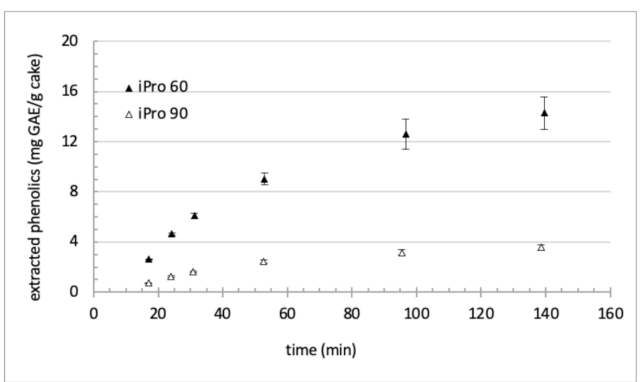

(b)

Figure 4. Extraction kinetics of (a) global extract and (b) total phenolic compounds using isopropanolbased solvents.

Looking first at ethanol-based solvents (Figure 3), the increase of the solvent hydration level increased the extraction rates of total extract and total phenols. The constant rate period that corresponds to the extraction of the most accessible compounds was about $30 \mathrm{~min}$. In that period, extraction is limited by solubility, and obviously, solubilization capacities were higher for EtOH 58, indicating therefore that more polar species were extracted. After the constant period, extraction rates decreased because diffusion now contributed to mass transfer, and less accessible solutes were extracted. The extraction of polyphenols continued after $30 \mathrm{~min}$, although for $\mathrm{EtOH} 58$ the rate progressively decreased. For that solvent, the global extraction considerably slowed down after $60 \mathrm{~min}$ with a curve that almost reached a plateau. On the contrary, for $\mathrm{EtOH} 86$ that was a less hydrated solvent, the extraction continued, indicating that the walnut cake still contained solutes to extract. The hydration level of the ethanolic mixture therefore influenced the extraction kinetics.

For isopropanol-based solvents, the water content also exerted a positive effect on the extraction of polyphenols. The effect was more pronounced than for ethanol-based solvents because of the very slow extraction rate observed with iPro 90. The extraction of polyphenols was not completed neither after $140 \mathrm{~min}$, though the extraction rates started to decrease. The striking difference with ethanol mixtures comes from the global extraction. Isopropanol 90 led to a far higher yield compared with iPro 60, and the difference between the two yields was maintained till the end of extraction. For isopropanol mixtures, the largest part of extractible compounds was thus already extracted at $100 \mathrm{~min}$ (at the volumeto-solid ratio of about 20), whatever the water content of the solvent.

Data reported in Table 1 evidenced the fact that oil was extracted by all solvents, while kinetics curves showed that extracted amounts and polyphenols were distributed differently among the collected fractions depending on the solvents. The aspect of fractions is visualized in Figure 5. Looking first at the color, one can see that the color intensity was fading as extraction progressed and ranged from a reddish color in F1 EtOH 58 and iPro 60 to pale yellow, with even a colorless solution for F6. Samples produced by using a higher water content (alcohol 60 vs. alcohol 90) or ethanol-based solvents appeared as slightly more colored. Red to yellow colors may be associated with the presence of carotenoids and flavonoids whose multiple conjugated double bonds give rise to such colors. In the collected fractions, the highest concentration of polyphenols was obtained for $\mathrm{F} 1 \mathrm{EtOH}$ 58 (2.8 mg GAE/ $\mathrm{mL}_{\text {solvent }}$ ) and F1 iPro 60 (1.9 mg GAE/ $\left.\mathrm{mL}_{\text {solvent }}\right)$, which were the most colored samples, while the least colored fractions corresponded to phenols concentrations below $0.15 \mathrm{mg} \mathrm{GAE} / \mathrm{mL}$. 

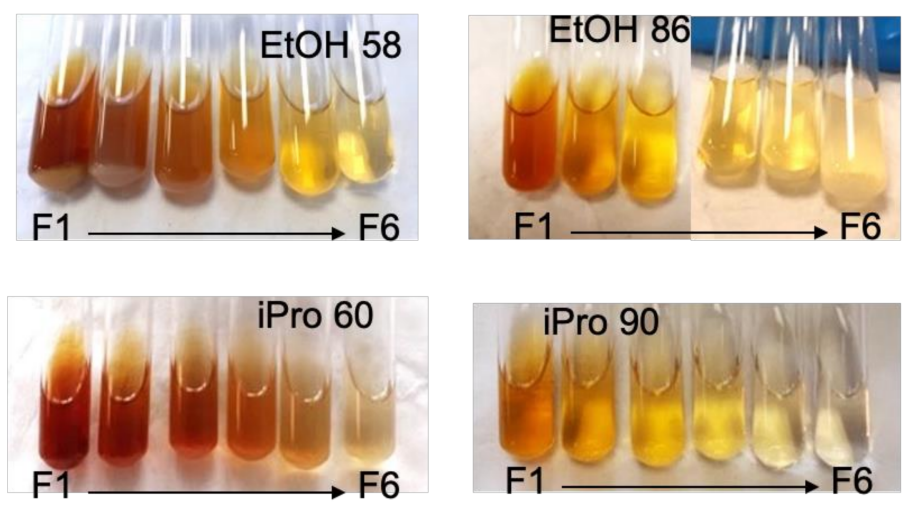

Figure 5. Visual aspect of fractions collected during extraction experiments, from the beginning of the extraction (F1) to its end (F6).

The presence of oil was visually detected as a separated phase or as dispersed droplets in the collected F1 and F2 samples, and up to F3 for iPro 90. A significant part of the extracted oil was therefore specially distributed over the three first fractions, that is, for a volume of solvent/mass of cake ratio of six. Some oil might exist in the other fractions, but at a concentration below the oil solubility limit. The solubility issue was also at stake for F1F2 EtOH 58, in which a sedimented phase was noticed, and for F1-F2 iPro 60 but to a lesser extent. Fractions represent what was extracted at $60^{\circ} \mathrm{C}$ but phase-separation or particles formation might occur when samples cooled down to room temperature because of the decreasing solubility with temperature. Though less visible on the pictures, fractions F4 to F6 EtOH 86 also contained a white bottom phase. This could be related to the specificity of EtOH 86 for which appreciable amounts of extracts were still produced after $80 \mathrm{~min}$ (Figure 3).

\subsection{Self-Emulsification of Extracts}

After desolventation by rotavap, the dried residues were rehydrated with pure water in order to assess their ability to self-emulsify. The hydration was carried out by adding water directly into the rotavap flask followed by sonication of the flask in an ultrasonic bath. Emulsions are created provided that there is an adequate balance between the oil and the surfactant molecules. Because of the different extracting ability of solvents and the different extraction kinetics, oil and polar surface-active molecules would be diversely distributed among the fractions whose concentrations were ranging from $120 \mathrm{mg}$ extract $/ \mathrm{mL}_{\text {water }}(\mathrm{F} 1$ iPro 90 ) to $5 \mathrm{mg}_{\text {extract }} / \mathrm{mL}_{\text {water }}$ (F6 EtOH 58).

The re-dispersion of extracts in water yielded to turbid and brownish dispersions (Figure 6).

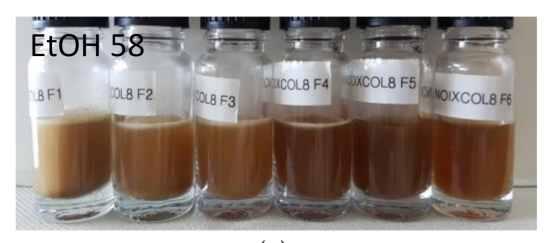

(a)

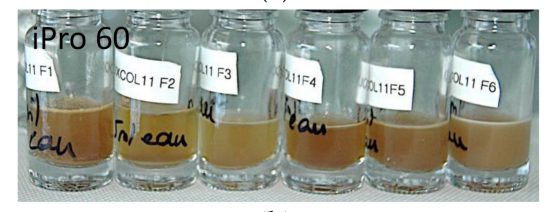

(b)

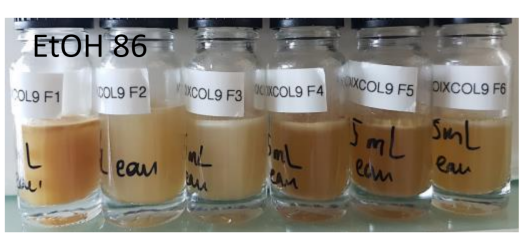

(b)

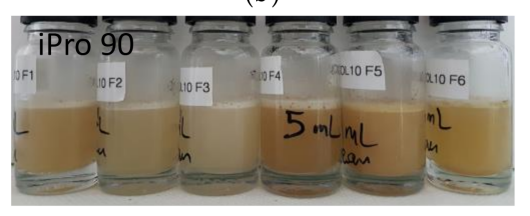

(c)

Figure 6. Aqueous dispersions obtained by hydrating the dried fractions collected during extraction with (a) EtOH 58, (b) EtOH 86, (c) iPro 60, (d) iPro 90. 
For several samples, a thin creamy layer developed upon resting, therefore confirming the presence of an emulsion. The layer corresponding to a concentrated emulsion and creaming is a usual phenomenon caused by the difference of densities of the continuous and dispersed phases. The observation of the re-homogeneized samples by optical microscopy showed the presence of droplets of sizes up to $100 \mu \mathrm{m}$ (Figure 7) proving therefore that endogenous surface-active components and oil were present simultaneously in several fractions. Since extracts were produced with alcohol-based solvents, the dispersion might contain compounds that became insoluble when the extracts were dispersed in pure water. Those materials are for instance seen in Figure 7 for the F4 EtOH 58 and F4 iPro 60 samples. It is worth noting that this particulated material can contribute to the creation of water-oil interfaces, as in the so-called Pickering emulsions [35].
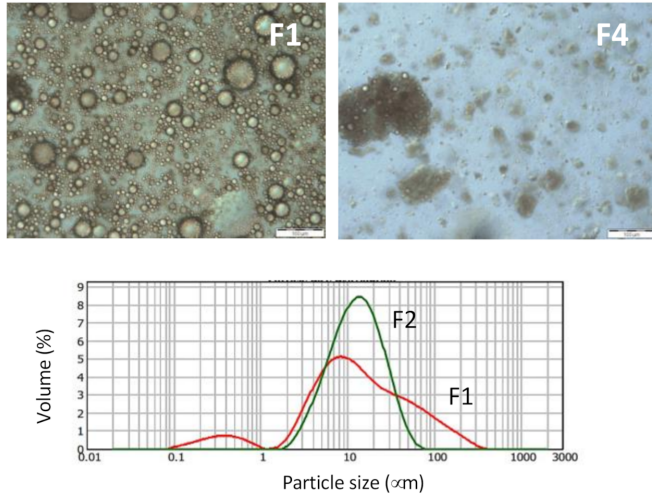

(a)
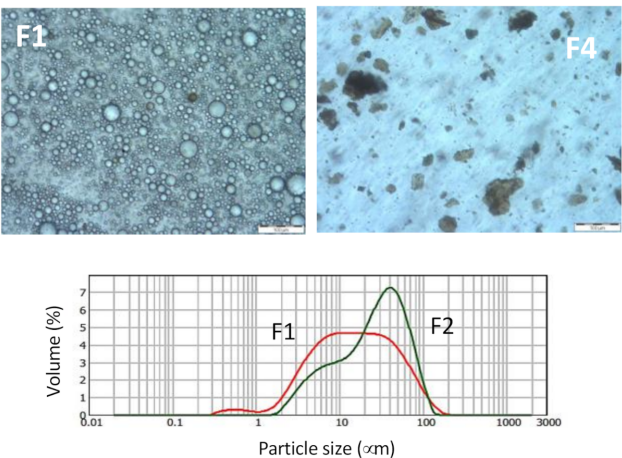

(c)
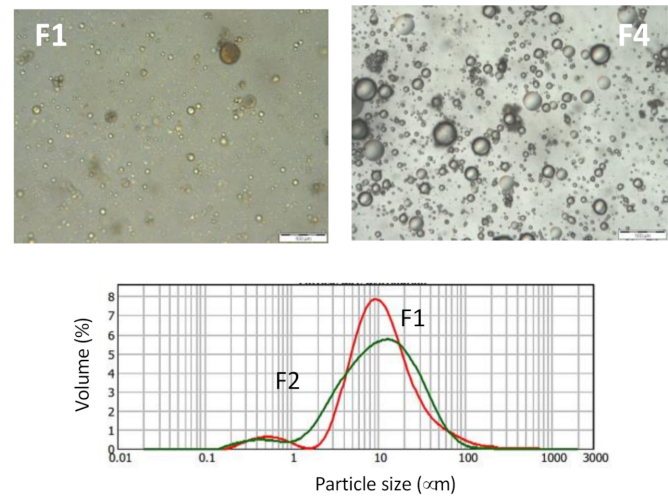

(b)
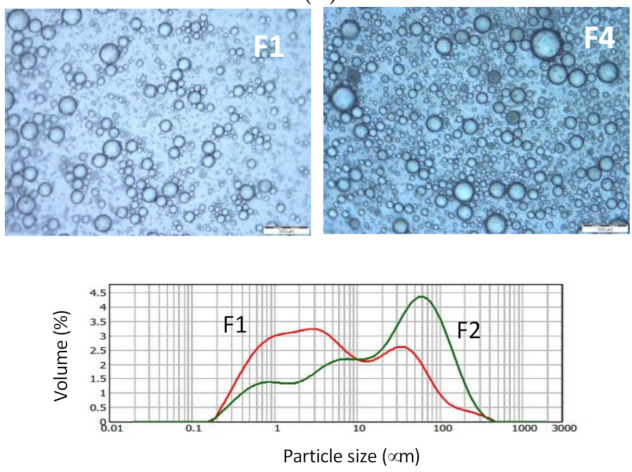

(d)

Figure 7. Aqueous dispersions obtained by hydrating dried fractions collected during extraction with (a) EtOH 58, (b) EtOH 86, (c) iPro 60, (d) iPro 90. Scale bar of $100 \mu \mathrm{m}$ for microscopy images; image of F1 iPro 90 obtained after dilution of the aliquot.

Analysis by light scattering diffraction evidenced a polydisperse distribution as well, with sizes ranging from 0.1 to $300 \mu \mathrm{m}$ in diameters (Figure 7). The analysis does not discriminate the nature of the diffracting objects; therefore, the reported distribution took into account droplets plus solid particles if present. Nevertheless, the sizes were rather fine if we consider the several steps of the dispersions fabrication (extraction-evaporationrehydration) and the variations of solubilization that these steps could induce.

To access the size of the droplet population only, the F1 samples were washed and centrifuged to remove any solid particles [35]. Microscopy images and size distribution are given in Figure 8. No measurement is reported for EtOH 86 since the final washed sample was too dilute. 

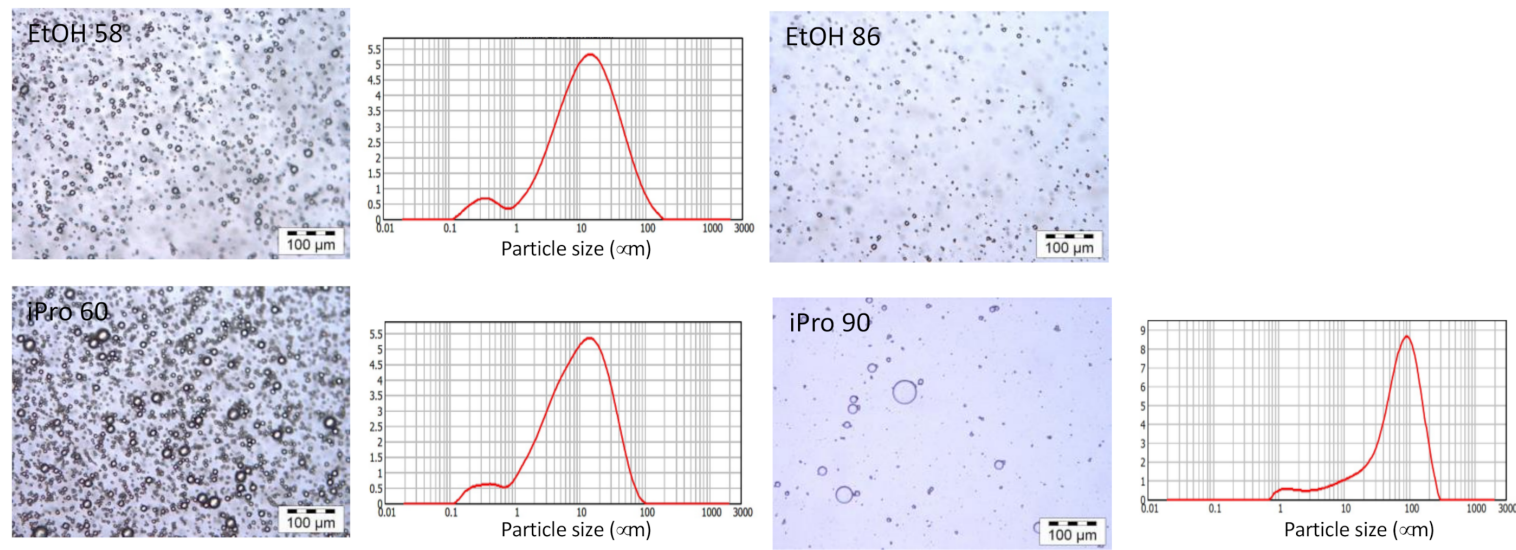

Figure 8. Characterization of washed F1 dispersions. Image of iPro 90 obtained after dilution of the aliquot; vertical axis for PSD is in volume \%.

Microscopy images and light scattering analysis showed the presence of polydisperse droplets ranging from 0.1 to $100 \mu \mathrm{m}$, a range similar to that of the unwashed F1 samples. Compared to the EtOH 58 and iPro 60 samples, the distribution of the iPro 90 sample was shifted toward the larger sizes. It was shown previously that iPro 90 extracted a lot of oil compared to the other solvents. The larger emulsion size could indicate that the sample did not contain enough surface-active compounds to accommodate the large amount of oil in the form of small drops. For the other solvents, a better combination of less oil and enough surfactants was probably achieved, allowing for the formation of smaller droplets.

The strategy of combining the extraction of active molecules (such as oil, phospholipids, polyphenols and proteins) and their formulation in oil-in-water emulsions was recently tested by Delvar et al. [58]. Dealing with a high shear mixer or the twin-screw extrusion of passion fruits, the emulsifying ability of the filtrates was assessed. Droplets below $10 \mu \mathrm{m}$ in diameter were obtained using an Ultraturax as an emulsifier. The filtrates, obtained after filtration on a $100 \mu \mathrm{m}$ tissue, contained 8.7 to $17.2 \mathrm{~g}$ of dry matter $/ 100 \mathrm{~g}_{\text {filltrate }}$ depending on the extraction process, among which 0.5 to $2.6 \mathrm{~g} / 100 \mathrm{~g}_{\text {filtrate }}$ was of oil. In our work, the concentrations of unwashed F1 and F2 dispersions were $12.0 \pm 1.2 \mathrm{~g} / 100 \mathrm{~mL}_{\text {water }}$ and $6 \pm 1 \mathrm{~g} / 100 \mathrm{~mL}_{\text {water }}$ for the iPro $90 \mathrm{~F} 1$ and F2 samples, $8.6 \pm 0.6 \mathrm{~g} / 100 \mathrm{~mL}_{\text {water }}$ and $2 \pm 1 \mathrm{~g} / 100 \mathrm{~mL}_{\text {water }}$ for F1, F2 EtOH $58,6 \pm 1 \mathrm{~g} / 100 \mathrm{~mL}_{\text {water }}$ and $2.1 \pm 0.3 \mathrm{~g} / 100 \mathrm{~mL}_{\text {water }}$ for F1, F2 EtOH 86 and iPro 60 . The dispersions were simply obtained by adding 4 or $5 \mathrm{~mL}$ of water to the dried extract followed by $3 \mathrm{~min}$ in an ultrasonic bath and were not filtrated unless for specific purposes. No emulsification process more energetic than an ultrasonic bath has been applied.

To go beyond the proof of concept aimed at in this work, a scale-up of the extraction technique should be carried out. By producing fractions of higher masses whose composition could be analyzed, and by washing the aqueous dispersions in order to access the size of droplets population only, one can expect to get a deeper insight at the results interpretation. So far, we can however conclude that in terms of emulsifying potential, the less hydrated solvents iPro 90 and EtOH 86 provided a better balance of oil and surface-active molecules over the entire extraction process, since emulsions were seen in all fractions. On contrary, for the more hydrated solvents iPro 60 and EtOH 58, emulsification occurred in the two to three first fractions, while in the following fractions, more particles and few smaller droplets coexisted. The F3 and F4 fractions were usually more heterogeneous, and there were more variations between replicates.

\section{Discussion and Conclusions}

Environmental and sustainability concerns prompt increased interest in alternative solvents for oil extraction, by-product valorization and minimal processing. At the crossroads 
of these concepts, the work aims to look for potential solvents to combine the extraction of oil and phenolic compounds from a healthy oleaginous by-product.

More specifically, the study evaluated the performance of four hydro-alcoholic solvents of a quite-high hydration level (from 10 to $42 \mathrm{vol} \%$ ) at producing complex extracts that would contain enough lipophilic and amphiphilic molecules to form emulsions upon rehydration and phenolic molecules for nutritional or antioxidative benefits. To refine the knowledge of the kinetics of extraction at short times and to optimize the consumption of solvent, a semi-continuous extraction design associated with a tight fractionated collection of the effluent was used. The results pointed out significant differences between the solvents.

Isopropanol 90 was the best solvent to recover oil from the press-cake. The oil extraction efficiency reached a value of $97 \%$ while the recovery stood in the range of $31 \%$ for $\mathrm{EtOH} 58$ and iPro 60 and 36\% for $\mathrm{EtOH} 86$. Due to this efficiency, the total extracted amount for iPro 90 was larger than that obtained with the other solvents. The increase of the solvent hydration level negatively influenced the oil extraction yield but positively increased the recovery of the phenolic compounds for both alcohols. Ethanol was a better extracting solvent than isopropanol for this class of compounds, and the highest value of $17.6 \mathrm{mg} \mathrm{GAE} / \mathrm{g}_{\text {cake }}$ was obtained by using EtOH 58. Regarding the self-emulsifying properties of extracts, several fractions contained enough surface-active material and oil to self-assemble as emulsions. These are generally the fractions obtained at short times, i.e., at a solvent/cake ratio of about 6-7. Emulsions can be also created by the presence of particles as in Pickering emulsions, so the presence of insoluble particles in the water dispersions should not be considered a drawback. Among the solvents, iPro 90 and $\mathrm{EtOH}$ 86 showed better performances in the sense that all extracts collected during the $140 \mathrm{~min}$ extraction were able to emulsify. Isopropanol 90 might be preferred because of the higher extraction yield it provides, but emulsions would be less rich in phenolic compounds. The most hydrated solvents were found to behave equally, with extraction yields in the same range for total extract, oil and phenolics and a limited emulsifying capacity of fractions.

From an industrial perspective, ethanol and isopropanol are suitable solvents to extract a complex mixture from a by-product such as walnut press-cake. On the basis of a $90 \%$ recovery of the extractable material, the use of iPro 90 and the collection of a single fraction cumulated up to a solvent volume-to-solid ratio of 11-13 is certainly the best choice, as it gives the highest mass of extract linked to the highest oil recovery. It can be assumed that the single fraction will emulsify, but this will have to be confirmed. If the target is the richness in polyphenols whilst oil is only a secondary benefit, one must choose EtOH 58 and a volume-to-solid ratio of 10 to obtain an extraction rate of $90 \%$; but it will be at the expense of a lower extracted mass and an emulsification that may not be the best. Whatever the solvents chosen, it is worth recalling that alcohols will have to be separated from the extracts before their use as pure extracts or as emulsions.

Author Contributions: Conceptualization and methodology, P.S.-P.; investigations: P.S.-P., M.d.P.G.-M., R.S. and C.H.-S.; formal analysis and data curation, P.S.-P., C.H.-S. and R.S.; writing-original draft preparation, review and editing, P.S.-P. All authors have read and agreed to the published version of the manuscript.

Funding: This research received no external funding.

Data Availability Statement: The datasets generated for this study are available on request to the corresponding author.

Acknowledgments: M.d.P.G.-M. acknowledges Colfuturo and Minciencias from Colombia for scholarship. The authors thank Moulin de la Veyssière, France, for the donation of the press-cake.

Conflicts of Interest: The authors declare no conflict of interest. 


\section{References}

1. Jahanban-Esfahlan, A.; Ostadrahimi, A.; Tabibiazar, M.; Amarowicz, R. A comparative review on the extraction, antioxidant content and antioxidant potential of different parts of walnut (Juglans regia L.) fruit and tree. Molecules 2019, 24, 2133. [CrossRef]

2. Gao, P.; Liu, R.; Jin, Q.; Wang, X. Effects of processing methods on the chemical composition and antioxidant capacity of walnut (Juglans regia L.) oil. LWT-Food Sci. Technol. 2021, 135, 100958. [CrossRef]

3. Martinez, M.; Labuckas, D.; Lamarque, A.; Maestri, D. Walnut (Juglans regia L.): Genetic resources, chemistry, by-products. J. Sci. Food Agric. 2010, 90, 1959-1967. [CrossRef] [PubMed]

4. Bakkalbasi, E.; Meral, R.; Dogan, I. Bioactive compounds, physical and sensory properties of cake made with walnut press-cake. J. Food Qual. 2015, 38, 422-430. [CrossRef]

5. Santos, J.; Alvarez-Orti, M.; Sena-Moreno, E.; Rabadan, A.; Pardo, J.; Oliveira, M.B. Effect of roasting conditions on the composition and antioxidant properties of defatted walnut flour. J. Sci. Food Agric. 2018, 98, 1813-1820. [CrossRef]

6. Bakkalbasi, E. Oxidative stability of enriched walnut oil with phenolic extracts from walnut press-cake under accelerated oxidation conditions and the effect of ultrasound treatment. J. Food Meas. Charact. 2019, 13, 43-50. [CrossRef]

7. Mao, X.; Hua, Y.; Chen, G. Amino Acid Composition, Molecular Weight Distribution and Gel Electrophoresis of Walnut (Juglans regia L.) Proteins and Protein Fractionations. Int. J. Mol. Sci. 2014, 15, 2003-2014. [CrossRef]

8. Sze-Tao, K.W.C.; Sathe, S.K. Walnuts (Juglans regia L): Proximate composition, protein solubility, protein amino acid composition and protein in vitro digestibility. J. Sci. Food Agric. 2000, 80, 1393-1401. [CrossRef]

9. Dai, J.; Mumper, R. Plant Phenolics: Extraction, Analysis and Their Antioxidant and Anticancer Properties. Molecules 2010, 15, 7313-7352. [CrossRef]

10. Arranz, S.; Perez-Jiménez, J.; Saura-Calixto, F. Antioxidant capacity of walnut (Juglans regia L.): Contribution of oil and defatted matter. Eur. Food Res. Technol. 2008, 227, 425-431. [CrossRef]

11. Luo, Y.; Wu, W.; Chen, D.; Lin, Y.; Ma, Y.; Chen, C.; Zhao, S. Optimization of simultaneous microwave/ultrasonic-assisted extraction of phenolic compounds from walnut flour using response surface methodology. Pharm. Biol. 2017, 55, 1999-2004. [CrossRef]

12. Ojeda-Amador, R.; Desamparados, M.; Gomez-Alonso, S.; Fregapane, G. Characterization of virgin walnut oils and their residual cakes produced from different varieties. Food Res. Int. 2018, 108, 396-404. [CrossRef]

13. Fregapane, G.; Guisantes-Batan, E.; Ojeda-Amador, R.; Desamparados Salvador, M. Development of functional edible oils enriched with pistachio and walnut phenolic extracts. Food Chem. 2020, 310, 125917. [CrossRef]

14. Garcia-Mendoza, M.P.; Espinosa-Pardo, F.A.; Savoire, R.; Etchegoyen, C.; Harscoat-Schiavo, C.; Subra-Paternault, P. Recovery and antioxidant activity of phenolic compounds extracted from walnut press-cake using various methods and conditions. Ind. Crops Prod. 2021, 167, 113546. [CrossRef]

15. Grosso, A.; Asensio, C.; Nepote, V.; Grosso, N. Antioxidant activity displayed by phenolic compounds obtained from walnut oil cake used for walnut oil preservation. J. Am. Oil Chem. Soc. 2018, 95, 1409-1419. [CrossRef]

16. Boidora, R.; Maestri, D. Phenolic Compounds from Nuts: Extraction, Chemical Profiles, and Bioactivity. J. Agric. Food Chem. 2020, 68, 927-942. [CrossRef] [PubMed]

17. Fukuda, T.; Ito, H.; Yoshida, T. Antioxidative polyphenols from walnuts (Juglans regia L.). Phytochemistry 2003, 63, 795-801. [CrossRef]

18. Labuckas, D.; Maestri, D.; Perello, M.; Martinez, M.; Lamarque, A. Phenolics from walnut (Juglans regia L.) kernels: Antioxidant activity and interactions with proteins. Food Chem. 2008, 107, 607-612. [CrossRef]

19. Carré, P. About solvents used in the preparation of oils for cosmetic products complying with the Cosmos standard. OCL 2021, 28, 16. [CrossRef]

20. Citeau, M.; Slabi, A.S.; Joffre, F.; Carré, P. Improved rapeseed oil extraction yield and quality via cold separation of ethanol miscella. OCL 2018, 25, D207. [CrossRef]

21. Citeau, M.; Regis, J.; Carré, P.; Fine, F. Value of hydroalcoholic treatment of rapeseed for oil extraction and protein enrichment. OCL 2019, 26, 1. [CrossRef]

22. Dagostin, A.; Carpiné, D.; Corazza, M. Extraction of soybean oil using ethanol and mixtures with alkyl esters (biodiesel) as co-solvent: Kinetics and thermodynamics. Ind. Crop. Prod. 2015, 74, 69-75. [CrossRef]

23. Baümler, E.; Carrin, M.; Carelli, A. Extraction of sunflower oil using ethanol as solvent. J. Food Eng. 2016, 178, 190-197. [CrossRef]

24. Capellini, M.; Chiavoloni, L.; Giacomini, V.; Rodrigues, C. Alcoholic extraction of sesame seed cake oil: Influence of the process conditions on the physicochemical characteristics of the oil and defatted meal proteins. J. Food Eng. 2019, 240, 145-152. [CrossRef]

25. Capellini, M.; Giacomini, V.; Cuevas, M.; Rodrigues, C. Rice bran oil extraction using alcoholic solvents: Physicochemical characterization of oil and protein fraction functionality. Ind. Crop. Prod. 2017, 104, 133-143. [CrossRef]

26. Navarro, S.; Capellini, M.; Aracava, K.; Rodrigues, C. Corn germ-bran oils extracted with alcoholic solvents: Extraction yield, oil composition and evaluation of protein solubility of defatted meal. Food Bioprod. Process 2016, 100, 185-194. [CrossRef]

27. Rodriguez, L.; Fernandez, M.; Pérez, E.; Crapiste, G. Performance of Green Solvents in the Extraction of Sunflower Oil from Enzyme-Treated Collets. Eur. J. Lipid Sci. Technol. 2021, 123, 2000132. [CrossRef]

28. Seth, S.; Agrawal, Y.C.; Ghosh, P.K.; Jayas, D.S.; Singh, B.P.N. Oil extraction rates of soya bean using isopropyl alcohol as solvent. Biosyst. Eng. 2007, 97, 209-217. [CrossRef] 
29. Zhang, F.; Rhee, K.C.; Koseoglu, S.S. Isopropyl alcohol extraction of cottonseed collets: Efficiency and performance. J. Food Lipids 2002, 9, 147-160. [CrossRef]

30. Sinichi, S.; Diosady, L. Isopropyl Alcohol Extraction of De-hulled Yellow Mustard Flour. J. Am. Oil Chem. Soc. 2014, 91, 2143-2153. [CrossRef]

31. McClements, D.; Gumus, C. Natural emulsifiers-Biosurfactants, phospholipids, biopolymers, and colloidal particles: Molecular and physicochemical basis of functional performance. Adv. Colloid Interface Sci. 2016, 234, 3-26. [CrossRef]

32. Dammak, I.; do Amaral Sobral, P.J.; Aquino, A.; das Neves, M.A.; Conte-Junior, C.A. Nanoemulsions: Using emulsifiers from natural sources replacing synthetic ones-A review. Compr. Rev. Food Sci. Food Saf. 2020, 19, 2721-2746. [CrossRef] [PubMed]

33. Marzocchi, S.; Anankabil, S.; Caboni, M.F.; Guo, Z. Enzymatic alkylsuccinylation of tyrosol: Synthesis, characterization and property evaluation as a dual-functional antioxidant. Food Chem. 2018, 246, 108-114. [CrossRef]

34. Rayner, M.; Marku, D.; Eriksson, M.; Sjöö, M.; Dejmek, P.; Wahlgren, M. Biomass-based particles for the formulation of Pickering type emulsions in food and topical applications. Colloids Surf. A: Physicochem. Eng. Asp. 2014, 458, 48-62. [CrossRef]

35. Joseph, C.; Savoire, R.; Harscoat-Schiavo, C.; Pintori, D.; Monteil, J.; Faure, C.; Leal-Calderon, F. Pickering emulsions stabilized by various plant materials: Cocoa, rapeseed press cake and lupin hulls. LWT_Food Sci. Technol. 2020, 130, 109621. [CrossRef]

36. Espinosa-Pardo, F.A.; Savoire, R.; Subra-Paternault, P.; Harscoat-Schiavo, C. Oil and protein recovery from corn germ: Extraction yield, composition and protein functionality. Food Bioprod. Process 2020, 120, 131-142. [CrossRef]

37. Lahtinen, M.; Valoppi, F.; Juntti, V.; Heikkinen, S.; Kilpeläinen, P.; Maina, N.; Mikkonen, K. Lignin-Rich PHWE Hemicellulose Extracts Responsible for Extended Emulsion Stabilization. Front. Chem. 2019, 7, 871. [CrossRef]

38. Ralla, T.; Herz, E.; Salminen, H.; Edelmann, M.; Dawid, C.; Hofman, T.; Weiss, J. Emulsifying Properties of Natural Extracts from Panax ginseng L. Food Biophys. 2017, 12, 479-490. [CrossRef]

39. Jarzebski, M.; Siejak, P.; Smułek, W.; Fathordoobady, F.; Guo, Y.; Pawlicz, J.; Trzeciak, T.; Łukasz Kowalczewski, P.; Kitts, D.; Singh, A.; et al. Plant Extracts Containing Saponins Affects the Stability and Biological Activity of Hempseed Oil Emulsion System. Molecules 2020, 25, 2696. [CrossRef]

40. Filotheou, A.; Ritzoulis, C.; Avgidou, M.; Kalogianni, E.; Pavlou, A.; Panayiotou, C. Novel emulsifiers from olive processing solid waste. Food Hydrocoll. 2015, 48, 274-281. [CrossRef]

41. Sabri, N.; Moulai-Mostefa, N. Formulation and Characterization of Oil-in-Water Emulsions Stabilized by Saponins Extracted from Hedera Helix Algeriensis Using Response Surface Method. Biointerface Res. 2020, 10, 6282-6292. [CrossRef]

42. Jin, F.; Wang, Y.; Tang, H.; Regenstein, J.; Wang, F. Limited hydrolysis of dehulled walnut (Juglans regia L.) proteins using trypsin: Functional properties and structural characteristics. LWT-Food Sci. Technol. 2020, 33, 110035. [CrossRef]

43. Moghadam, M.; Salami, M.; Mohammadian, M.; Emam-Djomeh, Z.; Jahanbani, R.; Moosavi-Movahedi, A. Physicochemical and bio-functional properties of walnut proteins as affected by trypsin-mediated hydrolysis. Food Biosci. 2020, 36, 100611. [CrossRef]

44. Zhu, Z.; Zhu, W.; Yi, J.; Liu, N.; Cao, Y.; Lu, J.; Decker, E.; McClements, D. Effects of sonication on the physicochemical and functional properties of walnut protein isolate. Food Res. Int. 2018, 106, 853-861. [CrossRef] [PubMed]

45. Wang, H.; Yao, L.; Lee, S.-L.; Wang, T. Extraction of Phospholipids from Egg Yolk Flakes Using Aqueous Alcohols. J. Am. Oil Chem. Soc. 2017, 94, 309-314. [CrossRef]

46. Price, N.; Fei, T.; Clark, S.; Wang, T. Extraction of phospholipids from a dairy by-product (whey protein phospholipid concentrate) using ethanol. J. Dairy Sci. 2018, 101, 8778-8787. [CrossRef]

47. Figueroa-Espinoza, M.C.; Zafimahova, A.; Maldonado Alvarado, P.; Dubreucq, E.; Poncet-Legrand, C. Grape seed and apple tannins: Emulsifying and antioxidant properties. Food Chem. 2015, 178, 38-44. [CrossRef]

48. Zhang, H.; Shin, J.A.; Hong, S.T.; Lee, K.T. Stability and antioxidant effect of rapeseed extract in oil-in-water emulsion. Korean J. Agricult. Sci. 2016, 43, 249-257. [CrossRef]

49. AOAC. Official Methods of Analysis, 17th ed.; Method 992.23; The Association of Official Analytical Chemists: Gaithersburg, MD, USA, 2000

50. Odabas, H.; Koca, I. Application of response surface methodology for optimizing the recovery of phenolic compounds from hazelnut skin using different extraction methods. Ind. Crop. Prod. 2016, 91, 114-124. [CrossRef]

51. Tir, R.; Dutta, P.; Badjah-Hadj-Ahmed, A. Effect of the extraction solvent polarity on the sesame seeds oil composition. Eur. J. Lipid Sci. Technol. 2012, 114, 1427-1438. [CrossRef]

52. Cornelio-Santiago, H.; Mazalli, M.; Rodrigues, C.; de Oliveira, A. Extraction of Brazil nut kernel oil using green solvents: Effects of the process variables in the oil yield and composition. J. Food Process Eng. 2019, 42, e1327. [CrossRef]

53. Sampaio Neto, O.; Batista, E.; Meirelles, A. The employment of ethanol as solvent to extract Brazil nut oil. J. Cleaner Prod. 2018, 180, 866-875. [CrossRef]

54. Sawada, M.; Venâncio, L.; Toda, T.; Rodrigues, C. Effects of different alcoholic extraction conditions on soybean oil yield, fatty acid composition and protein solubility of defatted meal. Food Res. Int. 2014, 62, 662-670. [CrossRef]

55. Oliveira, R.; Oliveira, V.; Kazue Aracava, K.; da Costa Rodrigues, C. Effects of the extraction conditions on the yield and composition of rice bran oil extracted with ethanol-A response surface approach. Food Bioprod. Process 2012, 90, 22-31. [CrossRef]

56. Kwiatkowski, J.; Cheryan, M. Extraction of Oil from Ground Corn Using Ethanol. J. Am. Oil Chem. Soc. 2002, 79, 825-830. [CrossRef] 
57. Malmberg, C.; Maryott, A. Dielectric Constant of Water from $0^{\circ}$ to $100{ }^{\circ}$ C. J. Res. Natl. Bur. Stand. 1956, 56, 2641. [CrossRef]

58. Delvar, A.; De Satgé-Caro, P.; Candy, L.; Caro, Y.; Cheong Sing, A.-S.; Raynaud, C. Integrated process for extraction and formulation in emulsions of active molecules from fresh passion fruits (Passiflora edulis Sims). J. Food Eng. 2019, 263, 388-397. [CrossRef] 